\title{
Investigation of the Changes in Surface Area and FT-IR Spectra of Activated Carbons Obtained from Hazelnut Shells by Physicochemical Treatment Methods
}

\author{
Aziz Şencan' ${ }^{1}$ and Mehmet Kılıç ${ }^{2}$ \\ ${ }^{1}$ Department of Chemical Engineering, Süleyman Demirel University, 32260 Isparta, Turkey \\ ${ }^{2}$ Department of Environmental Engineering, Süleyman Demirel University, 32260 Isparta, Turkey \\ Correspondence should be addressed to Mehmet Kılıç; mehmetkilic@sdu.edu.tr
}

Received 6 June 2015; Revised 13 November 2015; Accepted 22 November 2015

Academic Editor: Mohammad A. Al-Ghouti

Copyright (C) 2015 A. Şencan and M. Kılıç. This is an open access article distributed under the Creative Commons Attribution License, which permits unrestricted use, distribution, and reproduction in any medium, provided the original work is properly cited.

\begin{abstract}
In this study, raw hazelnut shells were used to obtain charcoal by pyrolysis at $250^{\circ} \mathrm{C}$. The obtained material was subjected to physical, chemical, and physicochemical treatment methods to obtain activated carbons (ACs). Effect of the treatment procedures was determined by measuring the surface area of the produced ACs. In addition, changes in the functional groups of the obtained ACs during these treatments were determined with the Fourier transform infrared spectroscopy (FT-IR). To determine the most effective chemical agent, the charcoal samples were examined for $\mathrm{Pb}(\mathrm{II})$ adsorption from aqueous solutions under different $\mathrm{pH}$ conditions of 4 to 6 . According to the results, the most effective chemical agent was determined as $\mathrm{Ca}(\mathrm{OCl})_{2}$. Effect of microwave and ultrasound treatments was also examined during $\mathrm{Pb}(\mathrm{II})$ adsorption by the chemically treated AC. The results showed that chemical treatment with $\mathrm{Ca}(\mathrm{OCl})_{2}$, microwave treatment for 5 minutes, ultrasound treatment for 20 minutes, and pyrolysis at $700^{\circ} \mathrm{C}$ together were the most suitable combination enhancing the surface area of the adsorbent. This combination increased the surface area and the adsorption capacity of the adsorbent by 202 and 4.76 times, respectively, when compared to those of the raw hazelnut shell.
\end{abstract}

\section{Introduction}

Hazelnut shell is an important agricultural residue that is used principally as a solid fuel in Turkey [1]. The shells account for the majority of the by-products of hazelnuts, as the kernel occupies less than $50 \%$ of the total nut weight [2]. The annual generation of the shells is in the range of $25-40 * 10^{4}$ tons in the Black-Sea region of Turkey [3]. The shells contain $24.2 \%$ cellulose, $28.2 \%$ hemicellulose, 34.6\% lignin, 9.7\% moisture, and $1.1 \%$ ash [4] and are disposed of as a low-value heat source or used as the raw material for furfural production [5].

Activated carbon (AC) adsorption is a widely used technique for the removal of organic and inorganic pollutants from the water and gases in the environment due to high surface area, high porosity, and specific surface chemistry [6]. Conversion of AC from biomass usually involves thermochemical carbonization such as combustion and pyrolysis followed by char activation. In the production of AC, pyrolysis is usually applied as a conversion process to carbonize biomass raw material into carbon rich precursor in the absence of oxygen [7]. Combustion is an oxidative pyrolysis process that is mostly used to extract energy from biomass of different forms in the presence of air or oxygen [8]. Both processes produce carbon rich residual in solid form such as char, a solid precursor for AC production.

The use of ACs is often suffering from the relatively low adsorption rate because of their microporous structures and long diffusion path through solid particles [9]. In addition, adsorption capacity of prepared ACs, especially for metal ions, depends on the effectiveness of acidic/polar oxygen functional groups present on its surface. Different oxidizing posttreatments can be conducted on ACs to stimulate the adsorption capability of functional groups on the surface. Yin et al. [10] recently reported several techniques to modify 
TABLE 1: Treatment methods applied for obtaining of different ACs from charcoal samples that were obtained by pyrolysis of raw hazelnut shells at $250^{\circ} \mathrm{C}$.

\begin{tabular}{lcc}
\hline & \multicolumn{1}{c}{ Treatment method } \\
Chemical treatment & Physicochemical treatment & Thermal treatment \\
\hline $\begin{array}{l}\text { Subjecting of chemical } \\
\text { agent solutions }\left(\mathrm{ZnCl}_{2},\right.\end{array}$ & $\begin{array}{c}\text { Applying of } \\
\text { (i) microwave treatment, }\end{array}$ & $\begin{array}{c}\text { Pyrolysis of } \\
\text { (i) the charcoal sample, }\end{array}$ \\
$\mathrm{KOH}, \mathrm{AlCl}_{3}$, and & (ii) ultrasound treatment (sonic wave infusion), & (ii) the chemically treated ACs, \\
$\left.\mathrm{Ca}(\mathrm{OCl})_{2}\right)$ to the charcoal & (iii) microwave and ultrasound treatment together \\
sample & to the charcoal sample during the chemical treatment & (iii) the physicochemically treated ACs \\
\hline
\end{tabular}

surface functional groups for enhancing the capability and selectivity for adsorption from aqueous medium.

Chemical activation process is generally based on the degradation of raw material with a chemical activator at a specific temperature. During chemical activation, raw material is mixed with an activator agent that acts as the dehydration substance and oxidizing medium. Various agents such as zinc chloride, phosphoric acid, aluminum chloride, magnesium chloride, potassium hydroxide, and sodium hydroxide can be used as activators, but zinc chloride, potassium hydroxide, and phosphoric acid are the most popular ones. Aforementioned agents disrupt the aromatic carbon skeleton and cause the formation of porous structures [11].

Fundamental mechanism of microwave heating includes exciting polar molecules or ions. Energy transfer via microwave does not happen through conduction as in classical heating. It changes depending on dielectric characteristics of the material [12]. Materials with higher dielectric constants better absorb microwaves and easily heat up. In short, only materials that absorb microwaves are relevant to microwave heating. These materials heat up according to two heating mechanisms called dipolar polarization and ionic transfer $[12,13]$. Average energy of a chemical bond is $84-335 \mathrm{~kJ} / \mathrm{mol}$ and the energy of microwave photons is around $0.123 \mathrm{~kJ} / \mathrm{mol}$. Thus, microwaves cannot directly affect or ionize the structure or break chemical bonds. At $2450 \mathrm{MHz}$ frequency, they can only affect the rotation of molecules. Only at this frequency, waves can easily progress through study material. Only kinetic energy of the molecules that get excited by absorbing microwave energy increases. Thus the energy that is required to pass activation energy barrier is provided and reaction proceeds faster [12]. Two different microwave technologies are used to prepare AC in the literature. In the first technology, biomass is carbonized at low temperatures and then exposed to microwaves, followed by another carbonization at higher temperatures. In the second technology, biomass is initially exposed to microwaves and then pyrolysed at desired temperatures. Studies where biomass was pyrolysed after chemical activation have been published recently [14-19].

It is now widely accepted that ultrasound power has a great potential to be used in a wide variety of industrial fields such as electrochemistry, food technology, nanotechnology, chemical synthesis, dissolution and extraction, dispersion of solids, phase separation, and water and sewage treatment, in addition to conventional applications in cleaning and plastic welding [20]. Ultrasound produces its mechanical and chemical effects through the formation and collapse of "cavitation" bubbles [21]. A significant amount of research has been published concerning this "sonochemical effect" and collected in various recent books [22,23]. Ultrasound exhibits also several beneficial mechanical effects in solid-liquid systems by means of the cavitations phenomenon; it enhances mass transfer rates, causes the formation of many microcracks on the solid surface, and thus increases the surface area between the reactants; it cleans solid reactant or catalyst particle surfaces [24].

From the data published in the concerning literature, it was thought that several surface modification methods such as chemical treatment, physicochemical treatment with microwave and/or ultrasound technologies, and thermal treatment might together affect the physicochemical properties of ACs. In this context, effectiveness of the examined treatment methods was evaluated (i) during $\mathrm{Pb}$ (II) adsorption from aqueous solutions by the obtained ACs under different $\mathrm{pH}$ conditions, (ii) by measuring surface area, and (iii) by comparing changes in the functional groups of raw hazelnut shell, charcoal samples, and the obtained ACs using FT-IR spectra.

\section{Materials and Method}

2.1. Adsorbent. Raw hazelnut shells were collected from Ünye in Turkey and then transported to the laboratory. After collection, the shells were thoroughly washed with distilled water to remove contaminants and then incubated at $60^{\circ} \mathrm{C}$ for 48 hours. Following this step, the shells were ground in grinding machine to reduce the size of the shells. To homogenize the sizes, shell pieces were sieved through two layers of sieves with 300- and 180-micron $(\mu \mathrm{m})$ pore sizes, respectively, and the pieces that remained between the sieves were collected. The collected materials were kept in a desiccator to ensure that they were not affected by the moisture of the environment until further studies.

2.2. Treatment Procedures. Treatment procedures were carried out for the purpose of increasing surface area and modifying surface functional groups of the charcoal sample in order to maximize adsorption capacity of the ACs obtained after treatment procedures. Explanations about how the treatment procedures were applied are given in Table 1.

2.2.1. Chemical Treatment. The charcoal samples were placed into $20 \%(\mathrm{w} / \mathrm{v})$ of $\mathrm{KOH}, \mathrm{ZnCl}_{2}, \mathrm{AlCl}_{3}$, and $\mathrm{Ca}(\mathrm{OCl})_{2}$ solutions at a mixing ratio of $15 \mathrm{~g}$ charcoal $/ 250 \mathrm{~mL}$ solution. Mixtures were stirred in room temperature for 24 hours and 
then filtered with filter papers for solid-liquid phase separation. Following this step, the samples were washed with 5\% $(\mathrm{v} / \mathrm{v})$ of $\mathrm{HCl}$ solution and then washed with distilled water until the $\mathrm{pH}$ of the washing water reached 7 . Then, the samples were dried, ground, and kept in a desiccator until the adsorption studies. In order to determine the most effective chemical agent, the samples were examined for $\mathrm{Pb}$ (II) adsorption from aqueous solutions under different $\mathrm{pH}$ conditions of 4 to 6 . After the most effective chemical agent and the optimum $\mathrm{pH}$ condition were determined, the obtained AC sample was subjected to the thermal treatment.

2.2.2. Physicochemical Treatment. Microwave and ultrasound applications were applied during the chemical treatment with the most effective chemical treatment agent. Microwave application took place at $100 \mathrm{~Hz}$ during the last 5 minutes of stirring phase of the chemical treatment. Ultrasound application took place at $85 \mathrm{~Hz}$ during the last 20 minutes of the chemical treatment. Following the treatment procedure, the obtained AC sample was subjected to the thermal treatment.

2.2.3. Thermal Treatment. Thermal treatment procedure was applied to the charcoal sample and the ACs that were initially obtained after the chemical and physicochemical (microwave-ultrasound procedures) treatments (Table 1). The procedure was carried out by pyrolysis of the examined material at a temperature condition of 250 or $700^{\circ} \mathrm{C}$. In this procedure, the samples, of which the size was reduced, were placed into steel capsules. To remove the oxygen from the environment, a great deal of nitrogen gas was released into the capsule. Then the capsules were immediately placed in an ash oven to obtain AC samples. The obtained AC samples were initially washed with distilled water to remove the remnants and left to dry in the oven at $60^{\circ} \mathrm{C}$ for 24 hours. Then, the samples were dried, ground, and kept in desiccators until the adsorption studies.

2.3. Adsorption Studies. Experimental conditions for temperature, kinetics, and isotherm were determined in our previous study [25] and these conditions were used in the current study. Adsorption experiments were carried out in duplicate for all of the examined conditions and experiments were repeated if the results were not close to each other. After shaking, the mixtures were filtered with $0.45 \mu \mathrm{m}$ filter paper (Millipore) to extract the adsorbent from the liquid phase. Concentration of $\mathrm{Pb}$ (II) ions in the filtrate was determined in the inductively coupled plasma (ICP) device.

To calculate the adsorption capacity, the following equation was used:

$$
Q_{e}=\frac{\left(C_{o}-C_{e}\right)}{m} * V
$$

where $Q_{e}$ is the amount of metal ions adsorbed on the sorbent at equilibrium $(\mathrm{mg} / \mathrm{g}) ; C_{o}$ is the initial metal ion concentration in solution $(\mathrm{mg} / \mathrm{L}) ; C_{e}$ is the effluent metal ion concentration $(\mathrm{mg} / \mathrm{L}) ; m$ is the dry weight of sorbent in the reaction mixture $(\mathrm{g})$; and $V$ is the volume of the reaction mixture (L).

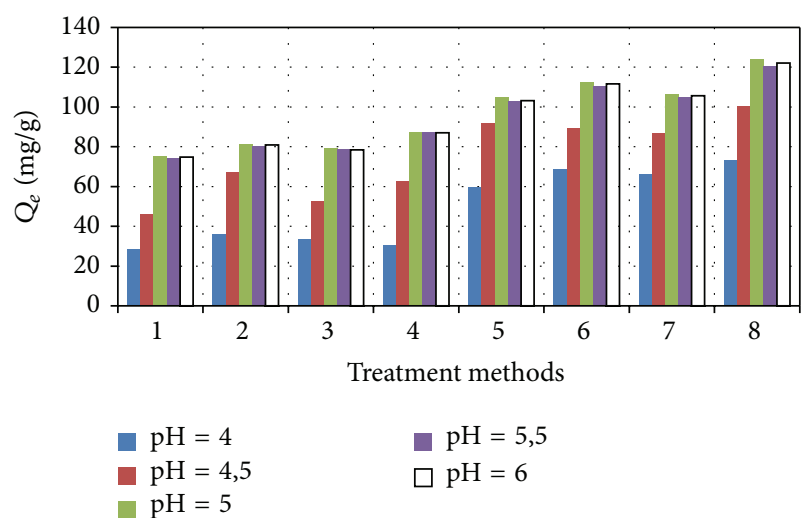

FIgURE 1: Adsorption capacities of the AC samples obtained by the chemical treatment followed by pyrolysis at 250 or $700^{\circ} \mathrm{C}$ (conditions: $C_{o}: 100 \mathrm{mg} / \mathrm{L}$, particle size: $180-300 \mu \mathrm{m}$, adsorbent dosage: $1 \mathrm{~g} / \mathrm{L}$, mixing speed: $150 \mathrm{rpm}$, mixing time: $60 \mathrm{~min}$, and temperature: $20^{\circ} \mathrm{C}$ ).

2.4. Surface Characterization of the ACs. BET surface area measurements and FT-IR spectrum analysis were carried out for the surface characterization of the charcoal samples and the obtained ACs. BET surface area measurements were carried out by Micromeritics device. FT-IR spectra were obtained with Spectrum BX FT-IR (Perkin Elmer Instruments).

\section{Results and Discussions}

3.1. Determining the Optimum Chemical Treatment Agent. Figure 1 shows the results of adsorption experiments carried out for determining the most effective chemical agent under different $\mathrm{pH}$ conditions ( $\mathrm{pH} 4$ to 6 ) and thermal treatment temperatures $\left(250\right.$ and $\left.700^{\circ} \mathrm{C}\right)$. According to the results, the highest adsorption capacity was obtained at $\mathrm{pH} 5$ by the $\mathrm{AC}$ treated with $\mathrm{Ca}(\mathrm{OCl})_{2}$ and it was found to be $87.2 \mathrm{mg} / \mathrm{g}$ and $123.8 \mathrm{mg} / \mathrm{g}$ at the temperature conditions of 250 and $700^{\circ} \mathrm{C}$, respectively. These results suggest that $\mathrm{Ca}(\mathrm{OCl})_{2}$ is a better chemical agent than the other agents. Thus, $\mathrm{Ca}(\mathrm{OCl})_{2}$ was used as the sole chemical agent for the following experiments.

Numbers on the horizontal axis are described in Table 2.

$\mathrm{Ca}(\mathrm{OCl})_{2}$ is used as a disinfectant in environmental engineering applications. The chlorine in its structure gives the following reaction with the AC:

$$
\mathrm{AC}+2 \mathrm{HOCl} \longrightarrow \mathrm{CO}_{2}+2 \mathrm{H}^{+}+2 \mathrm{Cl}^{-}
$$

As shown in (2), when chlorine contacts the AC, it causes structural deformations. Therefore, it is thought that this reaction caused more changes in the structure of $\mathrm{Ca}(\mathrm{OCl})_{2}$ than the other chemicals used. According to Girgis and El-Hendawy [26] chemical activation inflicts physical and chemical modifications on the original structure by penetrating particle swelling and partial dissolution of biomass, bond cleavage, and reformation of new polymeric structure resistant to thermal decomposition. 
TABLE 2: Description of the numbers in Figure 1.

\begin{tabular}{|c|c|c|c|c|c|}
\hline Number & Temperature $\left({ }^{\circ} \mathrm{C}\right)$ & Treatment & Number & Temperature $\left({ }^{\circ} \mathrm{C}\right)$ & Treatment \\
\hline 1 & \multirow{4}{*}{250} & $\mathrm{KOH}$ & 5 & \multirow{4}{*}{700} & $\mathrm{KOH}$ \\
\hline 2 & & $\mathrm{ZnCl}_{2}$ & 6 & & $\mathrm{AlCl}_{3}$ \\
\hline 3 & & $\mathrm{AlCl}_{3}$ & 7 & & $\mathrm{ZnCl}_{2}$ \\
\hline 4 & & $\mathrm{Ca}(\mathrm{OCl})_{2}$ & 8 & & $\mathrm{Ca}(\mathrm{OCl})_{2}$ \\
\hline
\end{tabular}

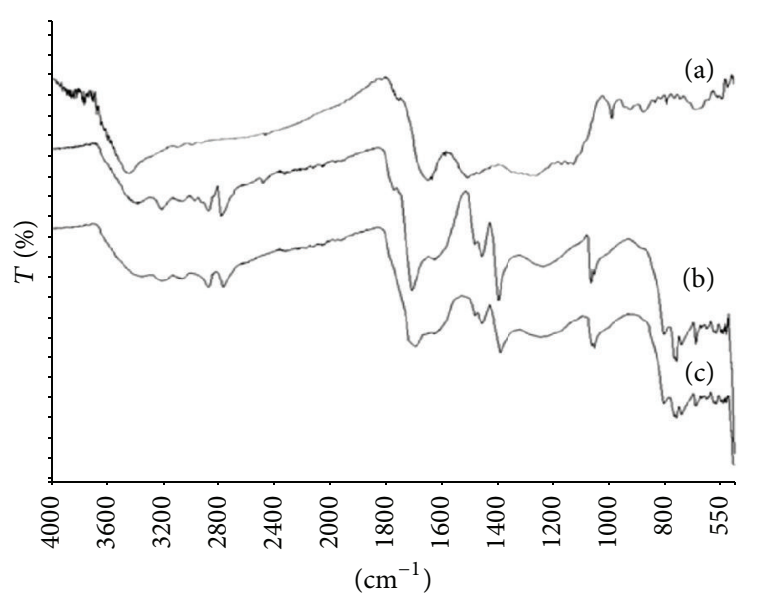

FIGURE 2: Spectrum of (a) the charcoal sample after pyrolysis at $250^{\circ} \mathrm{C}$, (b) the chemically treated AC followed by pyrolysis at $250^{\circ} \mathrm{C}$, and (c) the $\mathrm{Pb}$ (II)-loaded AC.

\subsection{Adsorption Mechanism of the AC Obtained by Chemical} Treatment. Figure 2 shows FT-IR spectrum of the charcoal sample obtained after the pyrolysis at $250^{\circ} \mathrm{C}$ and the $\mathrm{AC}$ obtained by the chemical treatment with $\mathrm{Ca}(\mathrm{OCl})_{2}$ followed by the pyrolysis at $250^{\circ} \mathrm{C}$ and the $\mathrm{Pb}$ (II)-loaded $\mathrm{AC}$.

When IR spectra of the charcoal sample (Figure 2(a)) and the AC sample treated with $\mathrm{Ca}(\mathrm{OCl})_{2}$ followed by the pyrolysis at $250^{\circ} \mathrm{C}$ (Figure 2(b)) are compared, it can be concluded that $\mathrm{Ca}(\mathrm{OCl})_{2}$, which is a strong oxidant, allowed increasing the amount of oxygen existing in the functional groups of the sample. This is proved by the observed bands which were formed after $\mathrm{Ca}(\mathrm{OCl})_{2}$ treatment at $2800-3200 \mathrm{~cm}^{-1}$ belonging to $\mathrm{O}-\mathrm{H}$ and at $1650-1700 \mathrm{~cm}^{-1}$ belonging to $\mathrm{C}-\mathrm{O}$ and $\mathrm{C}=\mathrm{O}$ groups. The decrease in transmittance $(\mathrm{T} \%)$ value of these bands after the adsorption was caused by $\mathrm{Pb}$ (II) which bonded with oxygen. Broadening of the band observed at $3200-3600 \mathrm{~cm}^{-1}$ is the $\mathrm{O}-\mathrm{H}$ vibrations of the water molecules adsorbing on the surface. After treatment with $\mathrm{Ca}(\mathrm{OCl})_{2}$, bands at $2800-3200 \mathrm{~cm}^{-1}$ belonging to $\mathrm{O}-\mathrm{H}$ vibrations sharpened. Sharpening was also observed in bands at 1650 $1700 \mathrm{~cm}^{-1}$ belonging to $\mathrm{C}-\mathrm{O}$ and $\mathrm{C}=\mathrm{O}$ groups. This shows that new carboxyl groups were formed by oxidation during treatment with $\mathrm{Ca}(\mathrm{OCl})_{2}$. In a study, Zolfaghari et al. [27] oxidized commercial AC with nitric acid and stated that the sharp bands which occurred around $1100-1700 \mathrm{~cm}^{-1}$ were caused by $\mathrm{C}-\mathrm{O}$ and $\mathrm{COOH}$ groups that were formed after oxidation. In the present study, FT-IR spectrum shows that the transmittance of the bands observed at $2800-3200 \mathrm{~cm}^{-1}$ and $1650-1700 \mathrm{~cm}^{-1}$ decreased after adsorption. This decrease can

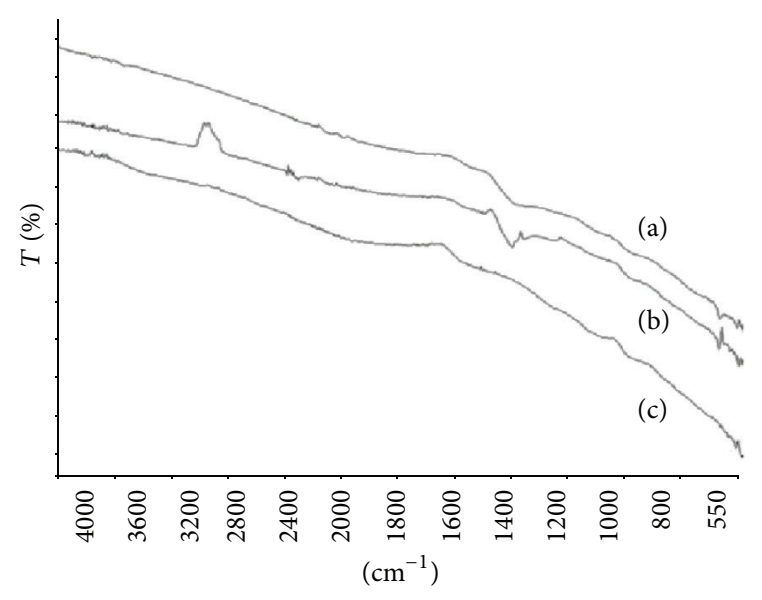

FIGURE 3: Spectrum of (a) the charcoal sample after pyrolysis at $700^{\circ} \mathrm{C}$, (b) the chemically treated AC followed by pyrolysis at $700^{\circ} \mathrm{C}$, and (c) the $\mathrm{Pb}(\mathrm{II})$-loaded $\mathrm{AC}$.

be explained by the fact that weak and broken bands such as $\mathrm{O}-\mathrm{H}$ and $\mathrm{C}-\mathrm{O}$, which resulted from $\mathrm{Pb}$ (II) bonding with carbonyl groups, could not be observed in the spectrum. Therefore, it was thought that $\mathrm{Pb}$ (II) ion may be chemically adsorbed on the surface of the AC.

When the spectra of the ACs obtained after the pyrolysis of the charcoal sample at $700^{\circ} \mathrm{C}$ (Figure 3(a)) and the treatment with $\mathrm{Ca}(\mathrm{OCl})_{2}$ followed by the pyrolysis at $700^{\circ} \mathrm{C}$ (Figure 3(b)) are compared, it can be seen that a distinctive band occurred around $1400 \mathrm{~cm}^{-1}$. A band at this region can only be attributed to methylene groups. Also, the band that is observed at $3000-3100 \mathrm{~cm}^{-1}$ reinforces the idea that this is an alkene. In the FT-IR spectrum of the AC used in the $\mathrm{Pb}(\mathrm{II})$ adsorption (Figure 3(c)), it can be seen that the mentioned bands belonging to alkenes disappeared in the spectrum, revealing that these bonds are metallic. The absence of distinctive bands at other regions of the spectra can be attributed to the structure being strongly carbonized. Danish et al. [28] activated the carbon obtained from a tree that is found around Australia, Acacia mangium, by calcium oxide and potassium hydroxide, and they evaluated the band at $1400 \mathrm{~cm}^{-1}$ in the FT-IR spectrum after the activation as the presence of carboxylate salt. In the present study, disappearance of this band after adsorption means that this carboxylate salt bonded with $\mathrm{Pb}$ (II) ions. Furthermore, it was thought that strongly carbonized structure physically adsorbed the $\mathrm{Pb}(\mathrm{II})$ ions. Since the sorbent was almost completely carbonized at $700^{\circ} \mathrm{C}$, the bonds carrying out the chemical adsorption process were deformed. 


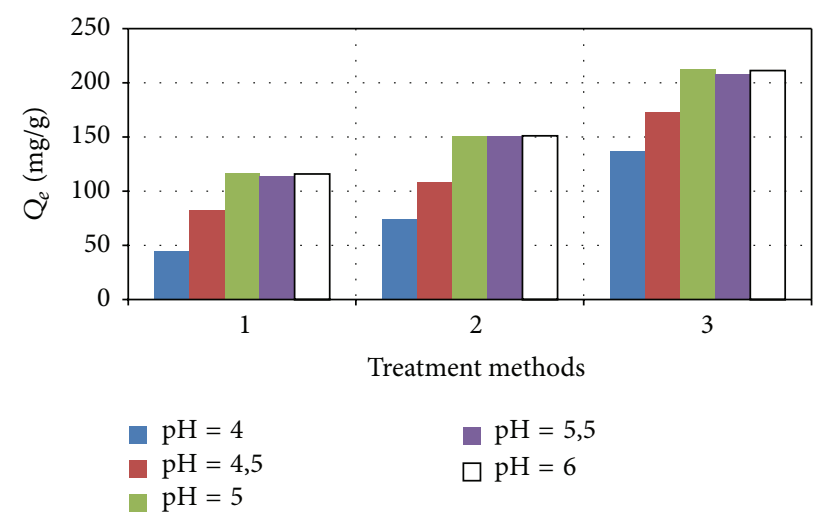

FIGURE 4: $\mathrm{Pb}(\mathrm{II})$ adsorption performance of the $\mathrm{AC}$ produced after physicochemical and thermal treatment.

3.3. Effect of the Physicochemical and Thermal Treatment on $\mathrm{Pb}(\mathrm{II})$ Adsorption. $\mathrm{Pb}(\mathrm{II})$ adsorption performances of the AC samples obtained after the physicochemical and thermal treatment are shown in Figure 4. According to the results, it can be clearly seen that both microwave and ultrasound treatment increased the adsorption capacities of the $\mathrm{AC}$ samples. The adsorption capacity of the AC that was treated with $\mathrm{Ca}(\mathrm{OCl})_{2}$ and then pyrolysed at $250^{\circ} \mathrm{C}$ was $87.2 \mathrm{mg} / \mathrm{g}$. When this sample was further treated with only microwaves, $\mathrm{Pb}$ (II) adsorption capacity of the resultant AC increased to $117.2 \mathrm{mg} / \mathrm{g}$. The treatment with ultrasound after microwave treatment further increased $\mathrm{Pb}$ (II) adsorption capacity of the AC to $151.2 \mathrm{mg} / \mathrm{g}$, meaning that the ultrasound treatment increased the adsorption capacity by nearly $30 \%$. In the case of increasing the pyrolysis temperature to $700^{\circ} \mathrm{C}, \mathrm{Pb}$ (II) adsorption capacity also increased to $212.3 \mathrm{mg} / \mathrm{g}$, implying that this treatment further increased the adsorption capacity by $40 \%$. Yağmur et al. [29] used microwave technology when producing ACs from the wastes of tea factories. While the micropore surface area of the AC obtained by $350^{\circ} \mathrm{C}$ pyrolysis without using microwave technology was $1.287 \mathrm{~m}^{2} / \mathrm{g}$, this value increased to $1.623 \mathrm{~m}^{2} / \mathrm{g}$ in the case of using microwave technology. Thus, it can be said that microwave treatment plays an important role in increasing the surface area. On the other hand, ultrasound technology has gained great importance in the relevant literature. However, there are not many studies on this topic in the literature. Şayan [30] used ultrasound treatment during AC production from hazelnut shells and increased the surface area of the hazelnut shell by 50 times. In the present study, surface area of the produced AC increased by 200 times by using microwave and ultrasound technologies together when compared to that of the raw hazelnut shell. This difference could be caused due to the chemical agent used in the treatment procedure and the pyrolysis temperature. Şayan [30] used $\mathrm{KOH}$ as the chemical agent and examined the pyrolysis temperature as $800^{\circ} \mathrm{C}$. Utilization of microwave and ultrasound technologies together could be another reason as well.

Numbers on the horizontal axis are described in Table 3.

Treatments on the adsorbent material also changed the surface area of the material. Surface area is significantly
TABLE 3: Description of the numbers in Figure 2.

\begin{tabular}{ll}
\hline Sample & Applied treatment procedure \\
\hline 1 & $\begin{array}{l}\text { Only microwave application during the chemical } \\
\text { treatment followed by pyrolysis at } 250^{\circ} \mathrm{C}\end{array}$ \\
\hline 2 & $\begin{array}{l}\text { Microwave and ultrasound applications together during } \\
\text { the chemical treatment followed by pyrolysis at } 250^{\circ} \mathrm{C}\end{array}$ \\
\hline 3 & $\begin{array}{l}\text { Microwave and ultrasound applications together during } \\
\text { the chemical treatment followed by pyrolysis at } 700^{\circ} \mathrm{C}\end{array}$ \\
\hline
\end{tabular}

important in the increase of adsorption capacity of the ACs. It was thought that the most important reason of the increase in the sorption capacity could be the increase in the surface area of the AC. Thus, the surface area of the AC was measured after each treatment. The results are presented in Table 4.

As shown in Table 4, the surface area of the raw hazelnut shell and the AC obtained by physicochemical and thermal treatments was measured as $5.92 \mathrm{~m}^{2} / \mathrm{g}$ and $1197.6 \mathrm{~m}^{2} / \mathrm{g}$, respectively. This result clearly implies that the surface area of the adsorbent material increased by nearly 202 times as a result of the treatment procedures. Furthermore, adsorption capacity also increased by 4.76 times. If the result of surface area of the charcoal sample and the AC obtained by physicochemical and thermal treatments are compared, it can be seen that surface area and adsorption capacity increased by 4.43 and 3.70 times, respectively.

The fundamental difference between conventional methods and microwaving is related to the production of the heat. Basic mechanism of microwave heating includes exciting polar molecules or ions. This stimulation happens under the effects of an electric and magnetic field. Unlike classical heating, energy transfer by microwaves does not happen by conduction. It changes depending on dielectric characteristics of the material [12]. Materials with higher dielectric constants better absorb microwaves and easily heat up. In short, only materials that absorb microwaves are relevant to microwave heating. These materials heat up according to two heating mechanisms called dipolar polarization and ionic transfer $[12,13]$. Average energy of a chemical bond is $84-335 \mathrm{~kJ} / \mathrm{mol}$ and the energy of microwave photons is around $0.123 \mathrm{~kJ} / \mathrm{mol}$. Thus, microwaves cannot directly affect or ionize the structure or break chemical bonds. At $2450 \mathrm{MHz}$ frequency, they can only affect the rotation of molecules. Only at this frequency, waves can easily progress through study material. Only kinetic energies of the molecules that get excited by absorbing microwave energy increase. Thus the energy that is required to pass activation energy barrier is provided and reaction proceeds faster [12].

Ultrasound waves are considerably different than electromagnetic waves. Organic materials adsorb ultrasound waves and they change into other materials through cavitation mechanism [31, 32].

3.4. FT-IR Analysis of the Pb(II) Adsorption with the ACs Obtained by Physicochemical and Thermal Treatment. FT-IR spectrum of the AC obtained by physicochemical treatment with only microwave application followed by pyrolysis at $250^{\circ} \mathrm{C}$ is shown in Figure 5(b). As expected, microwave 
TABLE 4: Effects of the treatment procedures on the $\mathrm{Pb}(\mathrm{II})$ adsorption capacity and surface area of the ACs.

\begin{tabular}{lcc}
\hline Properties of the adsorbent material & $\begin{array}{c}\text { Pb(II) adsorption } \\
\text { capacity }(\mathrm{mg} / \mathrm{g})\end{array}$ & $\begin{array}{c}\text { BET surface } \\
\text { area }\left(\mathrm{m}^{2} / \mathrm{g}\right)\end{array}$ \\
\hline Raw hazelnut shell & 44.6 & 5.92 \\
\hline Charcoal (after pyrolysis at $\left.250^{\circ} \mathrm{C}\right)$ & 57.3 & 270.2 \\
\hline Charcoal treated with $\mathrm{Ca}(\mathrm{OCl})_{2}$ followed by pyrolysis at $250^{\circ} \mathrm{C}$ & 87.2 & 471.49 \\
\hline $\begin{array}{l}\text { Charcoal treated with only microwave application during the chemical treatment } \\
\text { followed by pyrolysis at } 250^{\circ} \mathrm{C}\end{array}$ & 117.2 \\
\hline $\begin{array}{l}\text { Charcoal treated with microwave and ultrasound applications together during the } \\
\text { chemical treatment followed by pyrolysis at } 250^{\circ} \mathrm{C}\end{array}$ & 151.3 \\
\hline $\begin{array}{l}\text { Charcoal treated with microwave and ultrasound applications together during the } \\
\text { chemical treatment followed by pyrolysis at } 700^{\circ} \mathrm{C}\end{array}$ & 212.3 \\
\hline
\end{tabular}

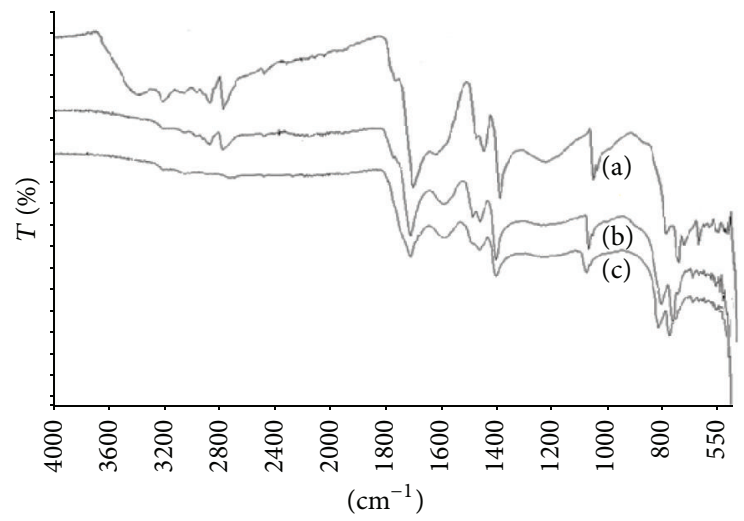

FIGURE 5: Spectra of (a) the chemically treated AC followed by pyrolysis at $250^{\circ} \mathrm{C}$, (b) the physicochemically treated $\mathrm{AC}$ with only microwave application followed by pyrolysis at $250^{\circ} \mathrm{C}$, and (c) the $\mathrm{Pb}(\mathrm{II})$-loaded AC.

treatment did not cause any change in the chemical structure of the AC. This result can be easily seen when the spectrum (Figure 5(b)) is compared with the spectrum of the AC which was not subjected to microwave treatment but only chemically treated followed by pyrolysis at $250^{\circ} \mathrm{C}$ (Figure 5(a)). There are small differences between Figures 5(b) and 5(c). It was thought that the decrease in transmittance value of the bands at $2800-3200 \mathrm{~cm}^{-1}$ belonging to $\mathrm{O}-\mathrm{H}$ vibrations and the bands at $1650-1700 \mathrm{~cm}^{-1}$ belonging to $\mathrm{C}-\mathrm{O}$ and $\mathrm{C}=\mathrm{O}$ groups after $\mathrm{Pb}(\mathrm{II})$ adsorption could be caused by $\mathrm{Pb}(\mathrm{II})$ bonding with oxygen. It was also thought that the adsorption capacity of the adsorbent increased because of the increasing surface area (Table 3 ).

From Figure 6, it can be seen that the ultrasound treatment affected the chemical structure of the AC. O$\mathrm{H}$ tension bands over $3200-3600 \mathrm{~cm}^{-1}$ and methylene and carbonyl bands over $1400-1600 \mathrm{~cm}^{-1}$ suggest that ultrasound treatment increased the interaction between the charcoal and $\mathrm{Ca}(\mathrm{OCl})_{2}$, thus increasing the number of carbonyl, hydroxyl, and methylene groups in the AC. It can be said that the decrease in transmittance value of these bands after $\mathrm{Pb}(\mathrm{II})$ adsorption is caused by metal ion binding on these sites. Şayan [30] found that increase in the amount of the pores of the AC prepared by the assisting of ultrasound treatment

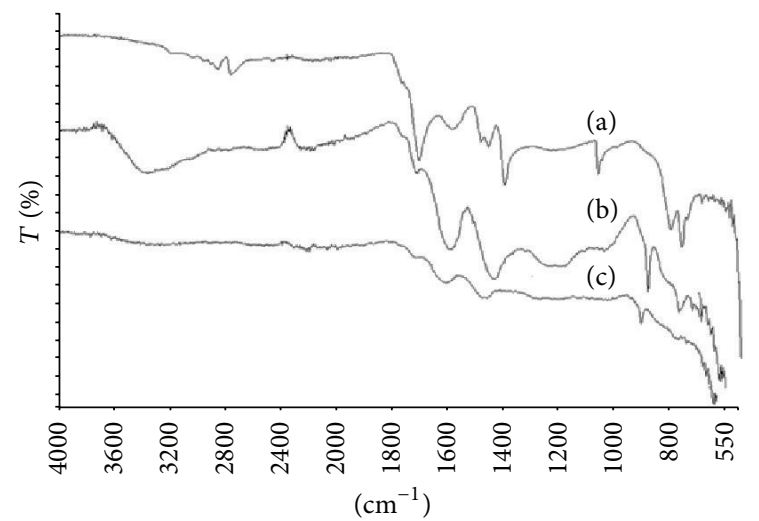

FIGURE 6: Spectra of (a) the physicochemically treated AC with only microwave application followed by pyrolysis at $250^{\circ} \mathrm{C}$, (b) the physicochemically treated AC with microwave and ultrasound applications together followed by pyrolysis at $250^{\circ} \mathrm{C}$, and (c) the $\mathrm{Pb}$ (II)-loaded AC.

could be remarkably seen in the SEM images. Bubble cavitation which occurred by ultrasound treatment supported the effect of the chemical agent to reach deeper in the structure of the material. Thus, the effectiveness of the functional groups existing in the obtained AC in the current study increased. Additionally, increasing pore amount increased the surface area of the AC, eventually leading to higher adsorption capacity.

Figure 7(b) shows the FT-IR spectrum of the physicochemically treated AC with microwave and ultrasound applications together followed by pyrolysis at $700^{\circ} \mathrm{C}$. When this spectrum is compared to that of the AC which was physicochemically treated with only microwave application followed by pyrolysis at $700^{\circ} \mathrm{C}$ (Figure 7(a)), it can be seen that there are no significant differences between both spectra. The bands over $3200-3600 \mathrm{~cm}^{-1}$ are caused by the $\mathrm{O}-\mathrm{H}$ vibrations of the water molecules adsorbing on the surface. Both of the AC samples were largely carbonized at higher temperature condition, implying that ultrasound-assisted treatment procedure did not play an important role in changing of the functional groups. However, ultrasound-assisted treatment procedure caused further increase in the surface area of the AC, thus increasing the adsorption capacity (Table 4 ). 


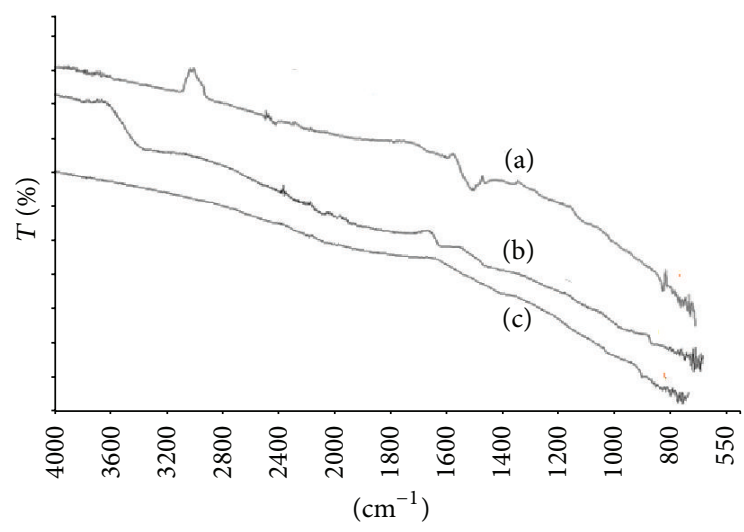

FIGURE 7: Spectra of (a) the physicochemically treated AC with only microwave application followed by pyrolysis at $700^{\circ} \mathrm{C}$, (b) the physicochemically treated $\mathrm{AC}$ with microwave and ultrasound applications together followed by pyrolysis at $700^{\circ} \mathrm{C}$, and (c) the $\mathrm{Pb}$ (II)-loaded AC.

\section{Conclusions}

This study was conducted with ACs obtained by chemical treatment which was assisted with microwave, ultrasound, and thermal treatments. While the adsorption capacity of the AC obtained by microwave and ultrasound treatments and pyrolysis at $250^{\circ} \mathrm{C}$ was $151.3 \mathrm{mg} / \mathrm{g}$, the value was found to be $212.3 \mathrm{mg} / \mathrm{g}$ for the AC obtained by microwave and ultrasound treatments but pyrolysed at $700^{\circ} \mathrm{C}$. In addition, BET surface area of the AC obtained by microwave and ultrasound treatments and pyrolysis at $250^{\circ} \mathrm{C}$ was $595.38 \mathrm{~m}^{2} / \mathrm{g}$ and the surface area of the AC obtained by microwave and ultrasound treatments but pyrolysed at $700^{\circ} \mathrm{C}$ was $1197.6 \mathrm{~m}^{2} / \mathrm{g}$. While microwave treatment did not affect the structure of the AC, ultrasound treatment increased the effectiveness of the functional groups of the AC. It was found that both microwave and ultrasound treatment increased the surface area of the AC. As a result of the study, it can be concluded that microwave and ultrasound treatment can be used in the preparation of ACs.

\section{Conflict of Interests}

The authors declare that there is no conflict of interests regarding the publication of this paper.

\section{Acknowledgments}

This project was funded by Süleyman Demirel University Scientific Research Project Foundation Fund (Project no. 2148-D-10). The financial assistance from Research Project Foundation Fund on "Determination of Lead(II) Sorption Capacity of Hazelnut Shell and Activated Carbon Obtained from Hazelnut Shell with Different Methods" is thankfully acknowledged by the authors.

\section{References}

[1] A. Demirbaş, "Kinetics for non-isothermal flash pyrolysis of hazelnut shell," Bioresource Technology, vol. 66, no. 3, pp. 247252, 1998.

[2] Y. X. Xu, E. N. Sismour, J. Parry, M. A. Hanna, and H. Li, "Nutritional composition and antioxidant activity in hazelnut shells from US-grown cultivars," International Journal of Food Science and Technology, vol. 47, no. 5, pp. 940-946, 2012.

[3] M. Dogru, C. R. Howarth, G. Akay, B. Keskinler, and A. A. Malik, "Gasification of hazelnut shells in a downdraft gasifier," Energy, vol. 27, no. 5, pp. 415-427, 2002.

[4] S. Uzuner and D. Cekmecelioglu, "A rapid screening approach to factors affecting dilute acid hydrolysis of hazelnut shells," International Proceedings of Chemical, Biological \& Environmental Engineering, vol. 50, pp. 30-33, 2013.

[5] A. Demirbaş, "Utilization of lignin degradation products from hazelnut shell via supercritical fluid extraction," Energy Sources, vol. 24, no. 9, pp. 891-897, 2002.

[6] A. M. M. Vargas, A. L. Cazetta, A. C. Martins et al., "Kinetic and equilibrium studies: adsorption of food dyes Acid Yellow 6, Acid Yellow 23, and Acid Red 18 on activated carbon from flamboyant pods," Chemical Engineering Journal, vol. 181-182, pp. 243-250, 2012.

[7] R. V. S. Silva, A. Casilli, A. L. Sampaio et al., "The analytical characterization of castor seed cake pyrolysis bio-oils by using comprehensive GC coupled to time of flight mass spectrometry," Journal of Analytical and Applied Pyrolysis, vol. 106, pp. 152-159, 2014.

[8] L. Sanchez-Silva, D. López-González, A. M. Garcia-Minguillan, and J. L. Valverde, "Pyrolysis, combustion and gasification characteristics of Nannochloropsis gaditana microalgae," Bioresource Technology, vol. 130, pp. 321-331, 2013.

[9] M. A. A. Zaini and M. J. Kamaruddin, "Critical issues in microwave-assisted activated carbon preparation," Journal of Analytical and Applied Pyrolysis, vol. 101, pp. 238-241, 2013.

[10] C. Y. Yin, M. K. Aroua, and W. M. A. W. Daud, "Review of modifications of activated carbon for enhancing contaminant uptakes from aqueous solutions," Separation and Purification Technology, vol. 52, no. 3, pp. 403-415, 2007.

[11] A. Sencan, Determination of lead(II) sorption capacity of hazelnut shell and activated carbon obtained from hazelnut shell with different methods [Ph.D. thesis], Süleyman Demirel Üniversitesi. Graduate School of Natural and Applied Sciences, 2011.

[12] C. R. Strauss and R. W. Trainor, "Developments in microwaveassisted organic chemistry: review," Australian Journal of Chemistry, vol. 48, no. 10, pp. 1665-1692, 1995.

[13] D. R. Baghurst and D. M. P. Mingos, "Superheating effects associated with microwave dielectric heating," Journal of the Chemical Society, Chemical Communications, no. 9, pp. 674-677, 1992.

[14] K. Y. Foo and B. H. Hameed, "Porous structure and adsorptive properties of pineapple peel based activated carbons prepared via microwave assisted $\mathrm{KOH}$ and $\mathrm{K}_{2} \mathrm{CO}_{3}$ activation," Microporous and Mesoporous Materials, vol. 148, no. 1, pp. 191-195, 2012.

[15] H. Deng, L. Yang, G. Tao, and J. Dai, "Preparation and characterization of activated carbon from cotton stalk by microwave assisted chemical activation-application in methylene blue adsorption from aqueous solution," Journal of Hazardous Materials, vol. 166, no. 2-3, pp. 1514-1521, 2009. 
[16] H. Chen and Z. Hashisho, "Fast preparation of activated carbon from oil sands coke using microwave-assisted activation," Fuel, vol. 95, pp. 178-182, 2012.

[17] M. Hejazifar, S. Azizian, H. Sarikhani, Q. Li, and D. Zhao, "Microwave assisted preparation of efficient activated carbon from grapevine rhytidome for the removal of methyl violet from aqueous solution," Journal of Analytical and Applied Pyrolysis, vol. 92, no. 1, pp. 258-266, 2011.

[18] T. H. Wang, S. X. Tan, and C. H. Liang, "Preparation and characterization of activated carbon from wood via microwaveinduced $\mathrm{ZnCl}_{2}$ activation," Carbon, vol. 47, no. 7, pp. 1880-1883, 2009.

[19] Q.-S. Liu, T. Zheng, P. Wang, and L. Guo, "Preparation and characterization of activated carbon from bamboo by microwaveinduced phosphoric acid activation," Industrial Crops and Products, vol. 31, no. 2, pp. 233-238, 2010.

[20] T. J. Mason, "Sonochemistry and sonoprocessing: the link, the trends and (probably) the future," Ultrasonics Sonochemistry, vol. 10, no. 4-5, pp. 175-179, 2003.

[21] J. G. Price, Current Trends in Sonochemistry, The Royal Society of Chemistry, Cambridge, UK, 1992.

[22] L. A. Crum, T. J. Mason, J. L. Reisse, and K. S. Suslick, Eds., Sonochemistry and Sonoluminescence, Kluwer Academic Publishers, Dordrecht, The Netherlands, 1990.

[23] R. V. Eldik and C. D. Hubbard, Chemistry under Extreme or Non-Classical Conditions, John Wiley \& Sons, New York, NY, USA, 1997.

[24] L. H. Thompson and L. K. Doraiswamy, "Sonochemistry: science and engineering," Industrial and Engineering Chemistry Research, vol. 38, no. 4, pp. 1215-1249, 1999.

[25] A. Şencan, M. Karaboyacı, and M. Kılıç, "Determination of lead(II) sorption capacity of hazelnut shell and activated carbon obtained from hazelnut shell activated with $\mathrm{ZnCl}_{2}$," Environmental Science and Pollution Research, vol. 22, no. 5, pp. 32383248, 2015.

[26] B. S. Girgis and A.-N. A. El-Hendawy, "Porosity development in activated carbons obtained from date pits under chemical activation with phosphoric acid," Microporous and Mesoporous Materials, vol. 52, no. 2, pp. 105-117, 2002.

[27] G. Zolfaghari, A. Esmaili-Sari, H. Younesi, and R. R. Baydokhti, "Surface modification of ordered nanoporous carbons CMK3 via a chemical oxidation approach and its application in removal of lead pollution from water," in Proceedings of the 2nd International Conference on Environmental Science and Technology, IPCBEE, vol. 6, pp. 174-178, Singapore, 2011.

[28] M. Danish, R. Hashim, M. N. M. Ibrahim, M. Rafatullah, T. Ahmad, and O. Sulaiman, "Characterization of Acacia mangium wood based activated carbons prepared in the presence of basic activating agents," BioResources, vol. 6, no. 3, pp. 3019-3033, 2011.

[29] E. Yağmur, M. Ozmak, and Z. Aktaş, "A novel method for production of activated carbon from waste tea by chemical activation with microwave energy," Fuel, vol. 87, no. 15-16, pp. 3278-3285, 2008.

[30] E. Şayan, "Ultrasound-assisted preparation of activated carbon from alkaline impregnated hazelnut shell: an optimization study on removal of $\mathrm{Cu}^{2+}$ from aqueous solution," Chemical Engineering Journal, vol. 115, no. 3, pp. 213-218, 2006.
[31] E. Çatalkaya and F. Şengül, “Ses İle kimyasal oksidasyon,” in IV Çevre Mühendisliği Kongresi, pp. 183-193, November 2001.

[32] N. Kardos and J.-L. Luche, "Sonochemistry of carbohydrate compounds," Carbohydrate Research, vol. 332, no. 2, pp. 115-131, 2001. 

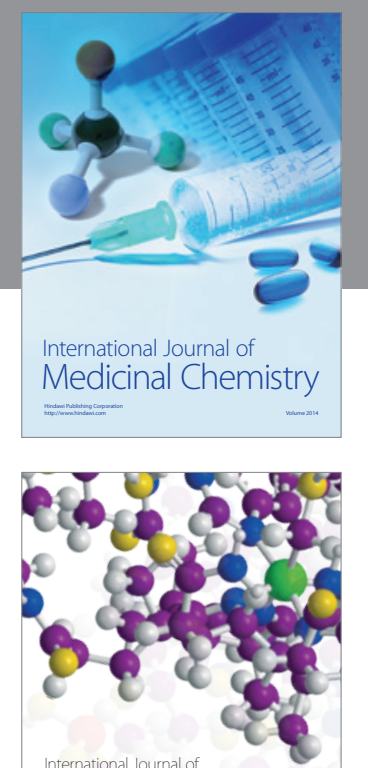

\section{Carbohydrate} Chemistry

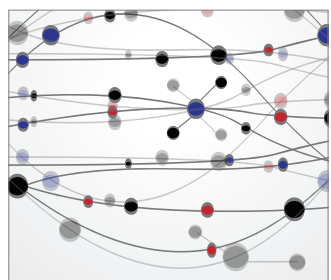

The Scientific World Journal
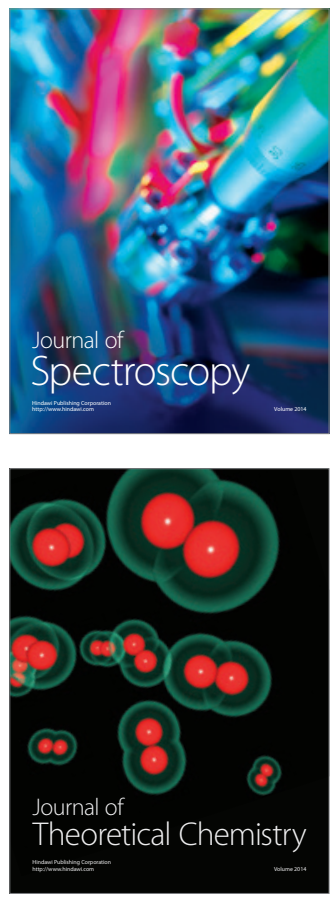
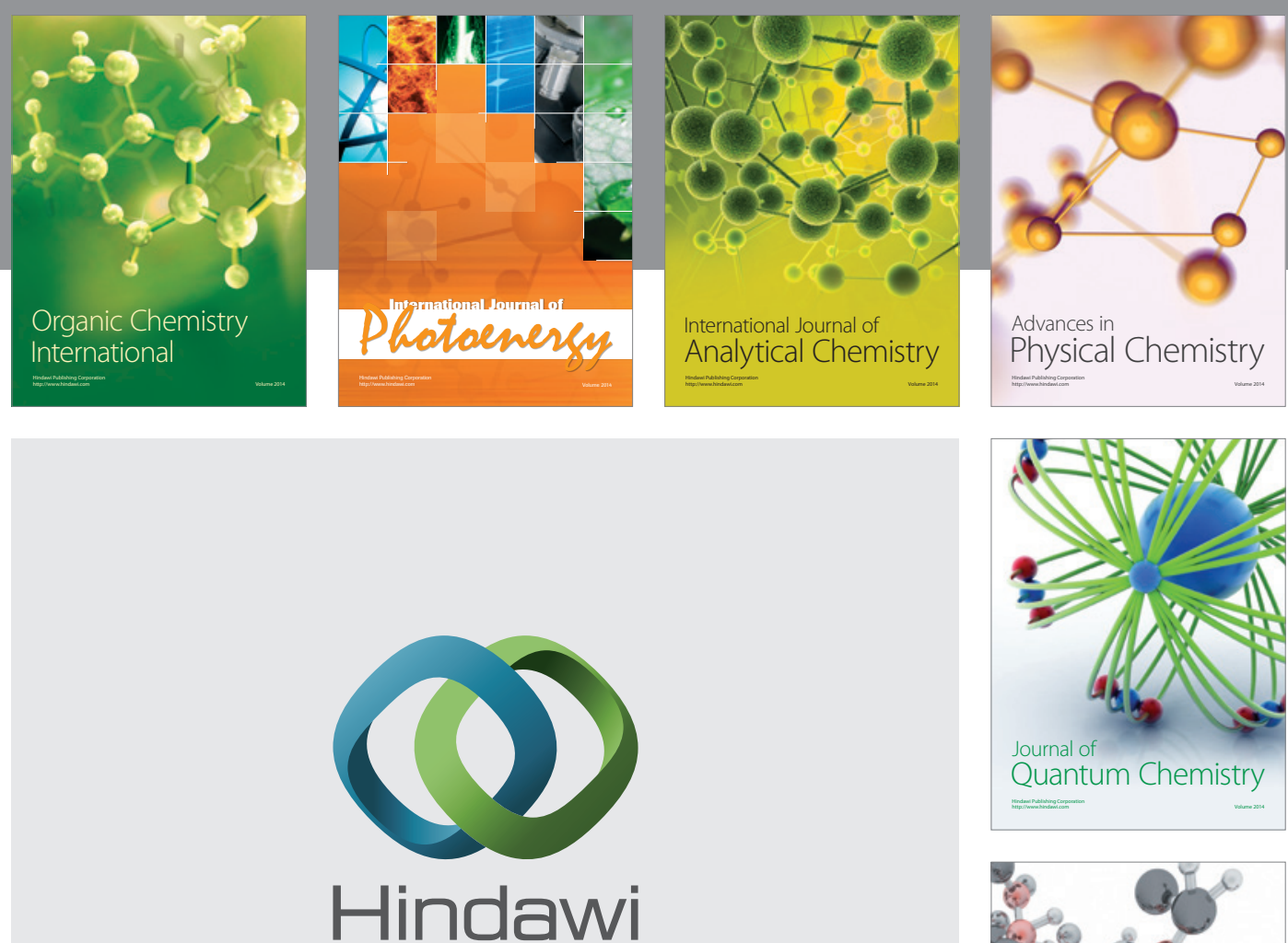

Submit your manuscripts at

http://www.hindawi.com

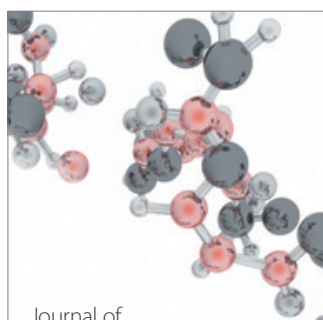

Analytical Methods

in Chemistry

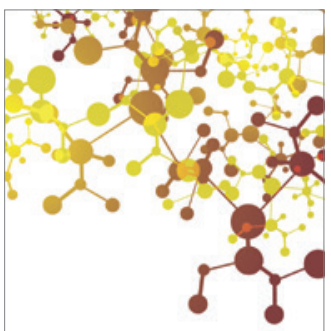

Journal of

Applied Chemistry

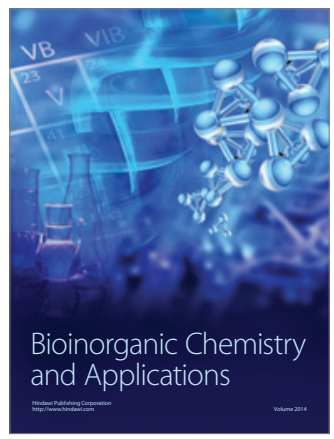

Inorganic Chemistry
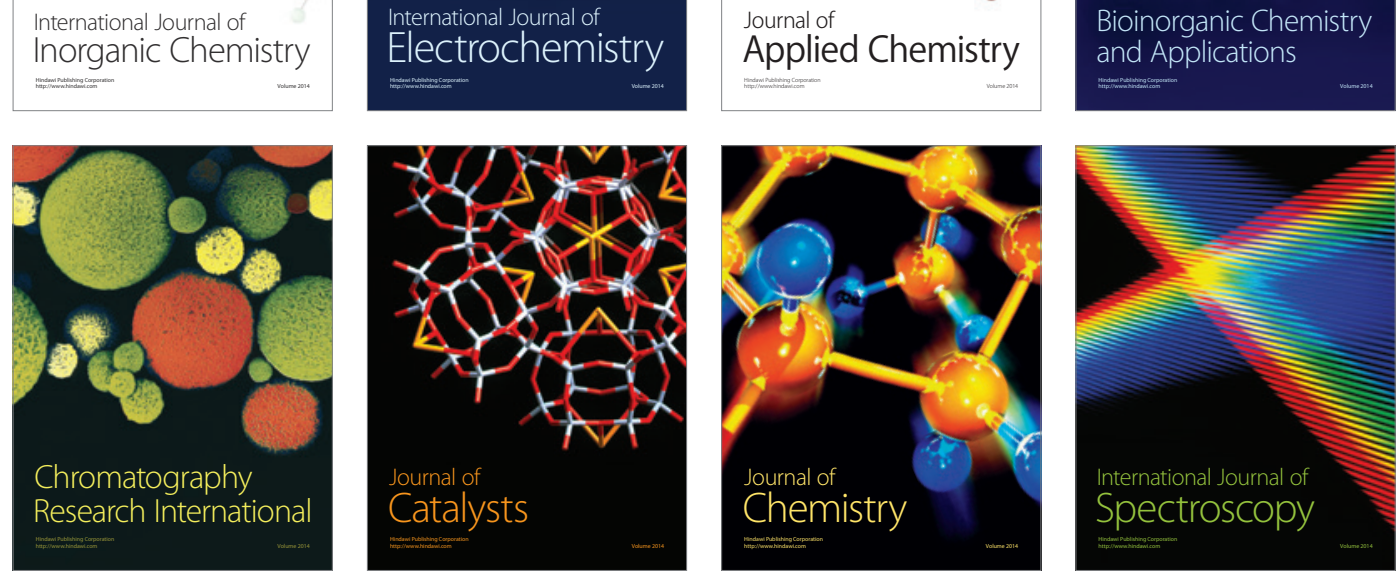